\title{
SOBRE EL SENTIDO, CONTENIDO Y CONFIGURACIÓN JURÍDICA DE LA ACCESIBILIDAD*
}

\author{
ON THE MEANING, CONTENT AND LEGAL CONFIGURATION OF \\ ACCESSIBILITY
}

\author{
Rafael de Asís**
}

\begin{abstract}
RESUMEN: En este trabajo se destaca el papel de la accesibilidad en el discurso de los derechos humanos. Para ello se expone su significado general tomando como referencia el diseño universal, en sus tres sentidos, y los ajustes razonables. El trabajo describe las diferentes construcciones jurídicas de la accesibilidad y sus límites.
\end{abstract}

ABSTRACT: This work highlights the role of accessibility in the human rights discourse. For this, its general meaning is exposed taking as reference the universal design, in its three senses, and the reasonable adjustments. The work describes the different legal constructions of the accessibility and its limits.

PALABRAS CLAVE: accesibilidad universal, diseño universal, ajustes razonables, discapacidad.

KEYWORDS: universal accessibility, universal design, reasonable accommodation, disability.

Fecha de recepción: 27/04/2020

Fecha de aceptación: 08/05/2020

doi: https://doi.org/10.20318/universitas.2020.5509

\footnotetext{
* Trabajo realizado en el marco de los proyectos "Madrid sin barreras: discapacidad e inclusión social en la Comunidad de Madrid" (S2015/HUM-3330) financiado por la Comunidad de Madrid y "Diseño, accesibilidad y ajustes. El eje de los derechos de las personas con discapacidad" (DER2016-75164-P) financiado por el Ministerio de Economía y Competitividad.

** Catedrático de Filosofía del Derecho. Instituto de Derechos Humanos. Universidad Carlos III de Madrid. E-mail: rafael.asis@uc3m.es
} 


\section{1.- ACCESIBILIDAD UNIVERSAL Y DERECHOS HUMANOS}

La accesibilidad es una idea esencial en cualquier contexto ${ }^{1}$. En términos generales buscamos que todo sea accesible. Este todo engloba productos, entornos, servicios, bienes, derechos... Además, hacer que las cosas sean accesibles es rentable desde un punto de vista económico. Por eso, cuando hacemos o queremos que algo no sea accesible, normalmente se nos exige alguna justificación.

Por otro lado, la falta de accesibilidad produce situaciones de discriminación y en ocasiones insatisfacción de derechos. De alguna manera, si la historia de los derechos humanos puede ser descrita como una historia de lucha contra la discriminación, no es descabellado subrayar como la accesibilidad, o si se quiere, el acceso al disfrute de los derechos, ha ocupado un importante papel en ella.

Si nos fijamos en las tres grandes reflexiones que están en el origen de la historia moderna de los derechos humanos, veremos como la lucha contra las barreras es una constante en todas ellas ${ }^{2}$. Así, la reflexión sobre la necesidad de limitar el poder político puede ser representada como el intento de eliminar las barreras que el poder establecía y que restringían la libertad de los individuos; por su parte, la reflexión sobre la tolerancia, buscaba eliminar las barreras que se encontraban determinadas iglesias y corrientes religiosas; por, último, la reflexión sobre la necesidad de humanizar el Derecho penal y procesal, tenía como objetivo rechazar ciertas normas que suponían verdaderas barreras para una correcta protección de los derechos, además de acabar con prácticas y normas contrarias a la dignidad. De esta forma, la eliminación de barreras presente en las tres reflexiones se traduce en una búsqueda de acceso a ciertos bienes que son considerados como valiosos y que justifican la existencia de los derechos.

Y esta idea de lucha contra barreras y acceso a bienes, será una constante en los diferentes procesos históricos de los derechos (positivación, generalización, internacionalización y especificación), en los que se trata de eliminar barreras que impiden el disfrute de los bienes y barreras que impiden la protección de los bienes. En todos ellos, la accesibilidad va de la mano de la igualdad y de la universalidad, dos de los grandes referentes del discurso de los derechos.

La idea de universalidad es también una constante del discurso de los derechos. Tomando como referencia de nuevo a los diferentes procesos históricos de los derechos, se trata de una idea que está claramente reflejada en el proceso de positivación y en el de internacionalización. Los principales textos del primero se refieren a

\footnotetext{
1 Vid. KALBAG, L., Accesibility for Everyone, A Book Apart, New York 2017.

2 Vid., AA.VV., Historia de los derechos fundamentales, Tomo I, Tránsito a la modernidad. Siglos XVI y XVII, (dirigido por Gregorio Peces-Barba y Eusebio Fernández), Universidad Carlos III-Dykinson, Madrid 1998.
} 
derechos naturales de todo ser humano, mientras que el segundo, está presidido precisamente por un texto que recoge esa dimensión en su propia formulación (la Declaración Universal de Derechos Humanos). Por otro lado, como es sabido, la génesis histórica de los derechos humanos se lleva a cabo a través de la aportación de dos grandes direcciones doctrinales: el iusnaturalismo racionalista y el contractualismo ${ }^{3}$. Y como ha señalado Pérez-Luño, ambas concepciones tienen en común el postular unas facultades jurídicas básicas comunes a todos los individuos ${ }^{4}$.

Igualmente es posible afirmar que se trata de una idea presente en los procesos de generalización y de especificación. No obstante, en estos su proyección es más problemática. En efecto, la principal característica del proceso de generalización es la extensión de la titularidad y el ejercicio de los derechos, lo que sin duda está en armonía con la universalidad. Sin embargo, las consecuencias de este proceso, se traducen en el reconocimiento de unos derechos cuya satisfacción no es universal. Tal vez la relevancia de los bienes sí es universal pero no el ejercicio de los derechos relacionados con ellos e incluso en ocasiones su titularidad. Y en relación con el proceso de especificación, algunos derechos fundamentales afectan exclusivamente a ciertos colectivos (niños, mujeres, mayores, personas con discapacidad, etc.), lo que sin duda condiciona la idea de universalidad. Sin embargo ésta permanece en términos de generalización (pertenecen a todas las personas mayores, a todas las mujeres, etc.), y la especificación se relaciona con supuestas situaciones de desventaja respecto a determinados bienes que otros colectivos tienen satisfechos o protegidos a través de ciertos instrumentos. En este punto, la universalidad se comprende si se observa en su relación con la igualdad.

La idea de igualdad está presente en el presupuesto del discurso sobre la justificación de los derechos y también en el sentido y el carácter de los bienes que estos protegen. Sólo es posible abandonarla defendiendo, por ejemplo, una visión parcial de la idea de individuo (por ejemplo otorgando valor moral sólo a aquellos que reúnan unas determinadas características) o dando prioridad a un tipo de derechos sobre otros (lo que normalmente va asociado a lo anterior). Y conviene hacer notar que la defensa de esas posiciones se enfrenta e incluso puede hasta llegar a situarse fuera de un discurso de los derechos.

La igualdad en este discurso se presenta como un criterio de distribución de los derechos (de los bienes que estos protegen) presentando dos proyecciones: la igualdad como diferenciación

\footnotetext{
3 Vid. FERNÁNDEZ, E., Teoría de la justicia y derechos humanos, Debate, Madrid 1984 , pp. 104 y ss.

${ }^{4}$ Vid. PÉREZ LUÑO, A.E., "La universalidad de los derechos humanos", en LÓPEZ GARCÍA, J.A. y DEL REAL, J.A., Los derechos: entre la ética, el poder y el Derecho, Dykinson, Madrid 2000, pp. 52 y ss.
} 
negativa y la igualdad como diferenciación positiva. La primera supone un trato igual de circunstancias o situaciones diferentes que, sin embargo, se estima deben considerarse irrelevantes para el disfrute o ejercicio de determinados derechos o para la aplicación de las normas. En relación con los derechos implica la no diferenciación en lo referido a su titularidad, ejercicio y garantías. Por su parte, la igualdad como diferenciación positiva, supone un trato diferente de circunstancias y situaciones que se consideran relevantes.

Dentro del proceso de generalización, es posible encontrarnos con el manejo de estas dos proyecciones de la igualdad. En efecto, aunque es común afirmar, que se trata de un proceso en el que la idea de igualdad formal es sustituida, o mejor compaginada, con la de igualdad material, no debe ser pasado por alto que una de las principales características de este proceso es la extensión de la satisfacción de los derechos a ciertos sujetos o colectivos, lo que en términos de igualdad se corresponde con la diferenciación negativa. Pero igualmente, este proceso plasmará también una idea de igualdad como diferenciación positiva a través de la aparición de los derechos económicos, sociales y culturales. Por su parte, en el proceso de especificación, la idea de igualdad que se maneja es la de la diferenciación positiva. Se trata de proteger a ciertos individuos y colectivos que se encuentran en una situación especial, a través del reconocimiento de derechos específicos.

De esta forma, universalidad e igualdad, son dos ideas estrechamente relacionadas y que se proyectan tanto en la dimensión ética de los derechos como en la jurídica5. Dentro de la dimensión ética, la universalidad expresa la atribución de un igual valor a todo ser humano lo que implica la exigencia de una consideración igualitaria de estos. En la dimensión jurídica, la consecución de esta idea exige un trato igual no incompatible con la atención a la diferencia $y$, por tanto, con el trato diferente. En este sentido, la teoría de los derechos, en su proyección jurídica, condicionada siempre por la dimensión moral, se abre a la posibilidad de la diferenciación positiva justificada. Y con ello, puede renunciar a la universalidad de los derechos siempre que ello no suponga renunciar a la universalidad ética. Dicho de otro modo, la teoría de los derechos en su aspecto jurídico, no exige la universalidad de los derechos, siempre y cuando se siga manteniendo el valor universal de los bienes que estos protegen. Aunque la diferenciación positiva implica dejar a un lado la universalidad, exige que las razones que la justifican sean coherentes con la universalidad ética.

5 DE ASÍS, R., "Hacia una nueva generalización de los derechos. Un intento de hacer coherente a la teoría de los derechos", en CAMPOY, I. (coord..), Una discusión sobre la universalidad de los derechos y la inmigración, Dykinson, Madrid 2006, pp. 35 y ss. 
Es importante así diferenciar, con Gregorio Peces-Barba, entre universalidad a priori y a posteriori ${ }^{6}$. Para el profesor Peces-Barba, la universalidad de los derechos afecta a su dimensión moral, es decir, a una característica de las pretensiones morales justificadas, que puede faltar cuando nos encontremos en la dimensión jurídica. La universalidad sería pues una característica de la moralidad de los derechos pero no necesariamente de su juridicidad.

La teoría de los derechos está abierta a la diferenciación siempre y cuando puedan aportarse razones morales no incompatibles con el propio discurso y por tanto, no contradictorias con la universalidad ética.

Lo anterior sirve para entender como se manifiesta la accesibilidad universal en el Derecho, compartiendo el ideal ético de la universalidad y la igualdad que no está reñido con el reconocimiento de la diferencia.

De esta forma, la accesibilidad universal en el discurso de los derechos exige la posibilidad de facilitar el acceso de todos a todo, dicho de otra manera, el acceso de toda persona a todos los derechos y a todos los bienes, lo que no está reñido con el trato diferente y específico.

No es así extraño que la accesibilidad universal se exprese en un primer momento a través de lo que se ha denominado como diseño universal o para todos.

Se trata de un principio que surge en la década de los años setenta del siglo $X X$ si bien a través del término "diseño sin barreras"7 y que se concreta en siete principios: (i) uso equitativo; (ii) uso flexible; (iii) uso simple e Intuitivo; (iv) información perceptible; (v) tolerancia al error; (vi) bajo esfuerzo físico; (vii) adecuado tamaño de acceso y uso.

El diseño universal exige que todo sea accesible, tanto lo ya elaborado, configurado o construido, como aquello que está por elaborar, configurar o construir. Por eso, se manifiesta en ocasiones a través de medidas (medidas de accesibilidad) que tratan de hacer accesible aquello que se hizo en un determinado momento, de manera justificada, como no accesible.

La implantación del diseño universal permite que el mayor número de personas (independientemente de su condición o situación) pueda comprender y usar bienes, productos, entornos y servicios, contribuyendo así a la satisfacción de la accesibilidad universal. No se expresa necesariamente en actuaciones generales, sino que puede manifestarse también como actuaciones concretas e incluso individuales.

\footnotetext{
6 Vid. PECES-BARBA, G., "La moralidad de los derechos humanos", en Tiempo de Paz, n. 29-30, 1993, pp. 10 y ss.

7 En la determinación de este principio, un arquitecto norteamericano Ron Mace, jugará un papel fundamental, destacando que no se trataba de una nueva ciencia sino de una toma de conciencia expresión del sentido común.
} 
La exigencia de accesibilidad que se manifiesta a través de la satisfacción de la obligación del diseño universal (en donde se engloban las medidas) no es así incompatible con tratos específicos. $\mathrm{Ni}$ tampoco esta exigencia es incompatible con tratos individuales o ajustes, cuando por alguna razón justificada el diseño no pueda producirse.

El diseño para todas las personas y los ajustes razonables son las estrategias a través de las cuales se satisface la exigencia de la accesibilidad universal. Su insatisfacción no justificada supone una clara discriminación, cuya relevancia aumenta si de lo que se trata es del acceso a un bien considerado como derecho.

Ahora bien, como no podría ser de otro modo, es posible encontrarnos con situaciones en las que se produzcan limitaciones a un derecho $\mathrm{y}$, por tanto, a la accesibilidad. En el ámbito de la accesibilidad, estas limitaciones van a ser, en general de dos tipos susceptibles de identificar con los términos de posibilidad y razonabilidad. Más adelante me referiré a ello.

De esta forma, la idea de accesibilidad acompaña la historia de los derechos y se convierte en un elemento clave de su propio concepto. Así, el disfrute de los derechos requiere de la posibilidad de acceso y su ausencia puede implicar una discriminación. Y también hay derechos cuyo contenido se expresa en forma de acceso a algún bien (sufragio pasivo) o como medio de acceso (derecho de asistencia letrada).

\section{2.- ACCESIBILIDAD UNIVERSAL Y DISCAPACIDAD}

La conexión entre accesibilidad y no discriminación acentúa la importancia de la primera en relación con personas y colectivos en situación de vulnerabilidad.

Como es sabido, la discapacidad "es un concepto que evoluciona y que resulta de la interacción entre las personas con deficiencias y las barreras debidas a la actitud y al entorno que evitan su participación plena y efectiva en la sociedad, en igualdad de condiciones con las demás" (Convención sobre los Derechos de las Personas con Discapacidad). De esta forma, la lucha contra las barreras es un componente esencial del discurso de los derechos de las personas con discapacidad.

Así, la accesibilidad, aunque es una exigencia universal ${ }^{8}$, cobra fuerza en el ámbito de la discapacidad, donde se vincula a la idea de posibilidad y aparece como discurso contra la discriminación.

\footnotetext{
8 Como señala el Dictamen del Comité Económico y Social Europeo (CESE), de 21 de enero de 2014, sobre "La accesibilidad como un derecho humano para las personas con discapacidad", del que fue ponente Yannis Vardakastanis (https://eur-lex.europa.eu/legalcontent/ES/TXT/?uri=CELEX\%3A52013IE3000\&from=EN\&lang3=choose\&lang $2=\mathrm{ch}$ oose\&lang1=EN), la accesibilidad es "un concepto válido para el conjunto de la
} 
$Y$ es que posibilidad y no discriminación son dos de los referentes de la reflexión sobre los derechos de las personas con discapacidad. La primera como alternativa a la "hegemonía" de la capacidad o, si se prefiere, a la construcción de lo humano desde el discurso abstracto de la capacidad ${ }^{9}$. La segunda como llamada de atención de la situación creada y no natural en la que se encuentran las personas con discapacidad.

En todo caso, la accesibilidad es un elemento esencial del discurso de la discapacidad o, si se prefiere, la discapacidad es una situación que surge, precisamente, por la falta de accesibilidad.

\section{1.- El marco general}

El artículo 9 de la Convención sobre los derechos de las personas con discapacidad (CDPD) se refiere a la accesibilidad universal afirmando: "A fin de que las personas con discapacidad puedan vivir en forma independiente y participar plenamente en todos los aspectos de la vida, los Estados Partes adoptarán medidas pertinentes para asegurar el acceso de las personas con discapacidad, en igualdad de condiciones con las demás, al entorno físico, el transporte, la información y las comunicaciones, incluidos los sistemas y las tecnologías de la información y las comunicaciones, y a otros servicios e instalaciones abiertos al público o de uso público, tanto en zonas urbanas como rurales".

Por su parte, la Ley General de los Derechos de las Personas con Discapacidad y de su Inclusión Social (LGDPD), en su artículo 2, al definir la accesibilidad, concreta la idea de acceso, haciendo referencia a la comprensión, el uso y la práctica: "es la condición que deben cumplir los entornos, procesos, bienes, productos y servicios, así como los objetos, instrumentos, herramientas y dispositivos, para ser comprensibles, utilizables y practicables por todas las personas en condiciones de seguridad y comodidad y de la forma más autónoma y natural posible".

\subsection{1.- Accesibilidad en sentido restringido y en sentido amplio}

Pero la accesibilidad está presente a lo largo de toda la CDPD. Aparece explícitamente, como ya hemos visto, en el artículo 9, en el que se vincula a ámbitos como el entorno físico, el transporte, la información y las comunicaciones, y a otros servicios e instalaciones abiertos al público o de uso público, tanto en zonas urbanas como rurales. Pero luego aparece en otros artículos como acceso a la

sociedad, y no únicamente para las personas con discapacidad" (punto 3.1 del Dictamen).

9 "La incursión de la discapacidad en la teoría de los derechos: posibilidad, educación, Derecho, poder", en CAMPOY, I. (ed.), Los derechos de las personas con discapacidad, Debates del Instituto Bartolomé de las Casas, n.2, Dykinson, Madrid 2004, pp. 59 y ss. 
información (arts. 9 y 21), la movilidad personal (art. 20), la educación (art. 24), la salud (art. 25), el empleo (art. 27), la protección social (art. 28), la participación política (art. 29) o la participación en el ocio, la cultura y el deporte (art. 30). Por su parte, en la LGDPD la accesibilidad aparece en el 5 y 22 vinculada a ámbitos como las telecomunicaciones y sociedad de la información; los espacios públicos urbanizados, infraestructuras y edificación; los transportes; los bienes y servicios a disposición del público; las relaciones con las administraciones públicas; la Administración de justicia; el Patrimonio cultural; el Empleo. Pero además, está luego presente al referirse a la toma de decisiones (art. 6), la salud (art. 10), educación (arts. 16 y 18), actividad profesional (art. 17), edificación (arts. 25 y 26), justicia (art. 28), empleo (art. 35 y ss.), protección social (arts. 48 y ss.), participación política (arts. 53 y ss.).

En este sentido, como he señalado en otros lugares, la accesibilidad posee dos sentidos: el restringido y el amplio. Y es que el artículo 9 de la CDPD menciona tres grandes derechos (vida independiente, de la participación en la vida social y de la igualdad de oportunidades) como justificación de la accesibilidad. Además, en el preámbulo de la Convención puede leerse que la accesibilidad es importante "para que las personas con discapacidad puedan gozar plenamente de todos los derechos humanos y las libertades fundamentales". Por su parte, la LGDPD, en su artículo 5, incorpora el acceso a la justicia y el empleo como ámbitos de accesibilidad.

La accesibilidad en un sentido restringido se proyecta en productos, objetos, instrumentos, herramientas, entornos, servicios...; la accesibilidad en un sentido amplio, se proyecta, además, en bienes y derechos.

\subsection{2.- El eje de la accesibilidad}

En otros trabajos me he referido al eje de la accesibilidad como el marco que sirve para identificar el sistema de derechos de las personas con discapacidad. Este eje está compuesto por el diseño universal y los ajustes razonables ${ }^{10}$.

Tal y como se establece en la LGDPD, la accesibilidad presupone la estrategia de «diseño universal o diseño para todas las personas», y se entienden sin perjuicio de los ajustes razonables que deban adoptarse" (art. 2).

Así, en un sentido integral, la accesibilidad se expresa de dos maneras: (i) como diseño universal, que funciona como un principio general fuente de obligaciones específicas, y que puede expresarse en sentido estricto o como medidas de accesibilidad; (ii) como ajuste

10 DE ASÍS, R., "El eje de la accesibilidad y sus límites", en Anales de Derecho y Discapacidad, núm. 1, 2016, pp. 51 y ss. 
razonable, que surgen cuando está justificado que el diseño universal no se haya satisfecho.

Conviene advertir, como ya he dicho al comienzo, que el eje de la accesibilidad no es un marco exclusivo de los derechos de las personas con discapacidad. Sin embargo, en lo que sigue me referiré a su proyección en ese ámbito.

El diseño universal en sentido estricto coincide con la definición de esta institución contenida en la CDPD: "el diseño de productos, entornos, programas y servicios que puedan utilizar todas las personas, en la mayor medida posible, sin necesidad de adaptación ni diseño especializado". En todo caso, es importante advertir que la LDGPD añade más proyecciones en consonancia con su forma de entender la accesibilidad: procesos, bienes, objetos, instrumentos, dispositivos, herramientas. Las medidas de accesibilidad no aparecen como tales en la CDPD aunque pueden equipararse, prácticamente, al diseño universal. El Comité sobre los derechos de las personas con discapacidad, se ha referido implícitamente a ellas cuando en el punto 24 del Comentario General núm. 2 sobre accesibilidad dice: "Debe hacerse una clara distinción entre la obligación de garantizar el acceso a todos los nuevos objetos, infraestructuras, bienes, productos y servicios que se diseñen, construyan o produzcan, y la obligación de eliminar las barreras y asegurar el acceso al entorno físico y el transporte, la información y la comunicación, y los servicios abiertos al público que ya existan" 11. La LGDPD las contempla al referirse en sus arts. 63, 65 y 66 a las exigencias de accesibilidad y a las exigencias de eliminación de obstáculos. Se trata de actuaciones que tienden a corregir situaciones en las que el diseño universal no se ha satisfecho de manera justificada, esto es, porque no era posible. Están dirigidas a convertir el producto, entorno, programa, servicio y/o derechos (como veremos inmediatamente) en utilizable, ejercible, practicable, comprensible.

Por su parte, los ajustes razonables son "las modificaciones y adaptaciones necesarias y adecuadas que no impongan una carga desproporcionada o indebida, cuando se requieran en un caso particular, para garantizar a las personas con discapacidad el goce o ejercicio, en igualdad de condiciones con las demás, de todos los derechos humanos y libertades fundamentales" (art. 2 CDPD). Ahora bien, la LGDPD añade que los ajustes están para facilitar la accesibilidad y la participación. Con carácter general, los ajustes razonables adquieren su significado cuando el bien de la accesibilidad no se puede satisfacer de manera universal, ya sea a través del diseño universal o de las medidas de accesibilidad, y se convierte así

11 Disponible en:

https://tbinternet.ohchr.org/_layouts/15/treatybodyexternal/Download.aspx?symbo Ino $=$ CRPD $/ \mathrm{C} / \mathrm{GC} / 2$ \&Lang $=\mathrm{en}$ 
en un auténtico derecho destinado a remediar esa situación individual $^{12}$.

La diferencia entre diseño ( $y$ medidas) y ajustes, tiene que ver, principalmente con el carácter general del primero, frente al individual del segundo. Esta diferencia ha servido a algunos para afirmar que el diseño universal es una estrategia insatisfactoria a la hora de abordar la accesibilidad real, apoyándose en la diversidad existente dentro de la discapacidad. Esto ha ocurrido, especialmente en el campo de la accesibilidad cognitiva.

No obstante, tanto en la CDPD como en la LGDPD se aclara que el diseño universal no excluirá los productos de apoyo para grupos particulares de personas con discapacidad, cuando lo necesiten. De alguna manera, esto supone una suerte de excepción a esa idea de diseño universal que descarta cualquier adaptación o diseño especializado. Esto significa que en ocasiones podrá entenderse como diseño medidas destinadas a grupos de personas con discapacidad ${ }^{13}$. De esta forma es posible hablar de un diseño universal impropio (dirigido a grupos de personas).

Así, el diseño universal se expresa de tres maneras: (i) en sentido estricto y propio, que supone tener en cuenta el acceso de las personas con discapacidad en la propia configuración de cualquier cosa; (ii) en sentido estricto impropio, que implica realizar actuaciones concretas de accesibilidad hacia grupos de personas con discapacidad en la configuración de cualquier cosa; (iii) medidas de accesibilidad, que implica realizar actuaciones destinadas a garantizar el acceso a cosas ya configuradas por parte de todas personas con discapacidad o por parte de grupos de personas con discapacidad.

\subsection{3.- El contenido de la accesibilidad}

Diseño y ajustes, aparecen en los dos sentidos de accesibilidad, el restringido y el amplio. Así, el diseño universal puede ser una obligación relacionada, por ejemplo, con el acceso o la práctica de un derecho $y$, lo mismo puede ocurrir con los ajustes, que pueden manifestarse como una adaptación necesaria para el acceso o la práctica de un derecho.

\footnotetext{
12 El diseño para todos ha sido especialmente reivindicado frente a las medidas de accesibilidad, como principio más acorde con una visión de la discapacidad no estigmatizadora, señalándose que las medidas de accesibilidad se enmarcan dentro de un discurso especial que no favorece la inclusión de las personas con discapacidad. En efecto se afirma que muchas de las políticas para favorecer la accesibilidad consisten en la adopción de medidas especiales para determinados colectivos o personas que perpetúan una imagen de "anormalidad" ciertamente incompatible con la filosofía del modelo social de la discapacidad.

13 Siendo esta una manera de superar las críticas dirigidas en ocasiones al diseño universal, en el sentido de que no sirve para todos a la vista de la diversidad humana.
} 
En todo caso, el contenido del eje de la accesibilidad en lo referido a las personas con discapacidad, esto es, el contenido del diseño y los ajustes, se expresa, en términos generales, a través de la idea de apoyo y asistencia. Y es que como hemos visto, el diseño implica configurar algo como susceptible de ser utilizado por todos, lo que incluye, diseño universal en sentido estricto y propio, tener en cuenta a las personas con discapacidad en su propia configuración (apoyar y asistir desde el principio el acceso); diseño universal en sentido estricto impropio, esto es, realizar actuaciones concretas hacia las personas con discapacidad (apoyar y asistir el acceso a través de adaptaciones generales); $y$, medidas de accesibilidad, generales a todas las personas o a las personas con discapacidad que participan de los sentidos anteriores. Por su parte, los ajustes suponen el apoyo o la asistencia al acceso dirigida a personas concretas en situaciones también concretas.

Los apoyos y la asistencia se pueden manifestar a través del diseño de técnicas, instrumentos o procedimientos, o también mediante la colaboración de personas.

De esta forma, como he señalado en otros lugares, es posible destacar dos grandes significados de los apoyos, estrechamente conectados. Por un lado, aquel que los conecta con el ejercicio de los derechos (los apoyos son necesarios para poder disfrutar de un derecho en igualdad de condiciones que los demás), como por ejemplo lo apoyos en el ámbito educativo o el empleo con apoyo, en el ámbito laboral. Por otro, aquel que los conecta con el ejercicio de la capacidad, que tiene que ver por tanto también con los derechos y, en concreto, con la toma de decisiones.

De igual manera, es posible referirse a tres grandes sentidos de asistencia, estrechamente relacionados. Por un lado aquel conectado con el ejercicio de los derechos, en relación con la vida independiente, identificándose con el primer significado de los apoyos. Por otro, aquel vinculado con lo que se entiende como actividades básicas (o fundamentales) de la vida diaria ${ }^{14}$. Por último, aquel vinculado a la atención al desarrollo y que constituye auténticos derechos (atención temprana, atención socio-educativa, atención socio-sanitaria).

Los apoyos y la asistencia pueden ser tratados de manera conjunta poseyendo cuatro proyecciones: (i) la del ejercicio de los derechos; (ii) la de la toma de decisiones; (iii) la de las actividades básicas (o fundamentales) de la vida diaria; (iv) la de la atención al desarrollo. En ocasiones, las dos últimas coinciden con la primera al ser la actividad o la atención el contenido de un derecho y, de esa forma, consustancial a su ejercicio.

Pues bien, dentro de los apoyos y la asistencia es posible diferenciar una proyección universal, en donde tienen cabida el

\footnotetext{
14 Art. 2 de la Ley española 39/2006 de promoción de la autonomía personal y atención a las personas en situación de dependencia.
} 
diseño (servicio de apoyo en un juzgado), incluso en su dimensión particular (servicio de apoyo a un colectivo de discapacidad concreto) y un ámbito individual, en donde entran en juego los ajustes (apoyo concreto a una persona).

\section{2.- La construcción jurídica}

El Comité sobre los derechos de las personas con discapacidad de Naciones Unidas, en su Observación General núm. 2, sobre la accesibilidad universal, relaciona a esta con el derecho de acceso. Como es sabido, este derecho aparece en el artículo 5,f) de la Convención Internacional sobre la Eliminación de todas las Formas de Discriminación Racial de 1965, en el que se afirma: "El derecho de acceso a todos los lugares y servicios destinados al uso público, tales como los medios de transporte, hoteles, restaurantes, cafés, espectáculos y parques".

En Sobre discapacidad y derechos ${ }^{15}$, retomando un discurso que elaboramos en un antiguo trabajo Sobre la accesibilidad universal en el Derecho ${ }^{16}$, señalaba la posibilidad de concebir la accesibilidad de cuatro formas diferentes, no excluyentes sino complementarias: como un principio jurídico, como parte del contenido esencial de todo derecho fundamental, como una exigencia de no discriminación y como un derecho a la accesibilidad de bienes, productos y servicios no relacionados con los derechos humanos.

Pues bien, dejando a un lado su presencia como principio jurídico, desde la diferenciación entre sentido restringido y sentido amplio de accesibilidad, es posible diferenciar tres construcciones jurídicas diferentes de la accesibilidad. Así, desde el sentido restringido, la accesibilidad puede aparecer como un derecho singular, mientras que desde el sentido amplio, puede aparecer como parte del contenido de los derechos humanos o como acción positiva.

El derecho a la accesibilidad, como derecho singular, es el derecho a la accesibilidad de bienes, productos y servicios no relacionados directamente con los derechos humanos. Es un derecho prestacional que posee como situación correlativa la obligación del diseño para todos. Se trata de un significado conectado con el discurso de los derechos de los consumidores y usuarios.

El derecho a la accesibilidad como parte del contenido de los derechos humanos, a su vez, puede tener diferentes proyecciones. En línea de principio, en este ámbito, la accesibilidad se presenta como el contenido esencial de todo derecho, incluidos los derechos fundamentales, y se manifiesta a través de aquellas medidas que permiten el acceso, el uso y la práctica de un derecho ${ }^{17}$. Se trata así

\footnotetext{
15 Dykinson, Madrid 2013.

16 Dykinson, Madrid 2007.

17 Como señaló el Tribunal Constitucional español en su sentencia de 8 de abril de 1981, el contenido esencial de un derecho es violado "cuando el derecho queda
} 
de una exigencia susceptible de defender jurídicamente al hilo de la defensa de cualquier derecho fundamental.

Ahora bien, en ocasiones, estos contenidos de accesibilidad que posibilitan el ejercicio de un derecho se han constituido en derechos singulares adquiriendo una individualidad propia. El alcance de estos derechos puede ser muy diferente. Piénsese por ejemplo en el derecho de acceso a la justicia o el derecho al intérprete (ambos puede entenderse como concreción del derecho al debido proceso, pero el segundo, incluso, como concreción del primero).

La construcción de la accesibilidad como derecho o como contenido de los derechos, permite también relacionarla con la no discriminación. Así, la ausencia de accesibilidad puede tener como resultado una situación de discriminación prohibida por nuestro artículo 14 de la Constitución (Sentencia del Tribunal Constitucional 269/1994, de 3 de octubre), y por el artículo 5 de la CDPD ${ }^{18}$.

Por último, es posible integrar en el eje de la accesibilidad a las acciones positivas ${ }^{19}$. Como es sabido, las acciones positivas son medidas que diferencian a favor de un colectivo desfavorecido y protegido constitucionalmente contra la discriminación y que tienen como objetivo su igualdad material como grupo ${ }^{20}$. En España, el artículo 2,g) de la Ley General de los derechos de las personas con discapacidad define a las medidas de acción positiva como, "aquellas de carácter específico consistentes en evitar o compensar las desventajas derivadas de la discapacidad y destinadas a acelerar o lograr la igualdad de hecho de las personas con discapacidad y su participación plena en los ámbitos de la vida política, económica, social, educativa, laboral y cultural, atendiendo a los diferentes tipos y grados de discapacidad". Respecto al contenido de las medidas de acción positiva, el artículo 68,1 dice: "Las medidas de acción positiva podrán consistir en apoyos complementarios y normas, criterios y prácticas más favorables". Así, se trata de acciones que se expresan también en términos de asistencia y/o apoyo ${ }^{21}$.

De esta forma, es posible relacionar las medidas de accesibilidad con las acciones positivas y entender a éstas como parte de la accesibilidad en sentido amplio. En contra de esta visión está el posicionamiento del Comité sobre los derechos de la personas con discapacidad quien en su observación núm. 6 sobre Igualdad y No

sometido a limitaciones que lo hacen impracticable, la dificultan más allá de lo razonable o lo despojan de la necesaria protección".

18 Vid. la Sentencia 3/2018, de 22 de enero de 2018 del Tribunal Constitucional.

19 Vid. MARTINEZ PUJALTE, A-L., Derechos fundamentales y discapacidad, CINCA, Madrid 2015, pp. 23 y ss. No en vano, la LGDPD, en su artículo 80, las introduce en el marco de la accesibilidad.

20 GIMÉNEZ GLUCK, D., Juicio de igualdad y Tribunal Constitucional, Bosch, Barcelona 2004, pp. 316 y ss.

${ }^{21}$ En España por ejemplo, el empleo con apoyo es configurado por la normativa como acción positiva. Vid. el Real Decreto 870/2007, de 2 de julio, por el que se regula el programa de empleo con apoyo como medida de fomento de empleo de personas con discapacidad en el mercado ordinario de trabajo. 
Discriminación señala, al diferenciar los ajustes de las medidas de acción positiva, que se trata de "medidas específicas implican un trato preferente a las personas con discapacidad respecto de las demás para solucionar la exclusión histórica y sistemática o sistémica de los beneficios derivados del ejercicio de los derechos". Pues bien, en mi opinión, las medidas de acción positiva no son privilegios sino medidas de lucha contra la discriminación que se diferencian de los ajustes en que son colectivas $y$, en este sentido, tienen que ver, principalmente, con las medidas de accesibilidad. Un ejemplo de este tipo de medidas serían las cuotas dentro del mercado laboral.

\section{3.- Los límites}

La diferenciación entre la accesibilidad como derecho singular y la accesibilidad como parte del contenido los derechos, es fundamental a la hora de analizar sus límites, sobre todo teniendo en cuenta de que en el segundo caso, nos desenvolvemos en el ámbito de los derechos fundamentales.

En este ámbito, como es sabido, los límites sólo son admisibles si se trata de bienes y derechos de igual valor, y existe una diferenciación entre los ámbitos público (obligación de respetar, de promover y de prestar) y privado (obligación de respetar y de promover).

Pues bien, en otros lugares señalé la posibilidad diferenciar tres grandes tipos de límites a la accesibilidad: (i) los límites de lo necesario (tipo de bienes, productos o servicios sobre los que se proyecta la accesibilidad); (ii) los límites de lo posible (situación del conocimiento científico, diversidad humana, carga, actitudinal); (iii) los límites de lo razonable (ausencia de justificación de la accesibilidad al afectar a otros derechos y bienes 0 al constituir un coste desproporcionado).

Sin embargo, es difícil referirse a los límites de lo necesario en relación con la accesibilidad. Estos límites aparecen cuando la ausencia de accesibilidad está justificada al demandarse ésta en ámbitos no relacionados con la vida independiente, la participación social y la igualdad de oportunidades. Y es difícil encontrar un ámbito ajeno a estos tres referentes (incluyen lo privado y lo público, lo individual y lo social, la ausencia de discriminación). Otra cosa ocurre con los otros dos tipos de límites.

Los límites de lo posible que se proyectan básicamente sobre el diseño universal ${ }^{22}$ tienen tres sentidos.

\footnotetext{
22 No olvidemos que la LGDPD, en su artículo 2, al definir la accesibilidad, concreta la idea de acceso, haciendo referencia a la comprensión, el uso y la práctica ojo habla también de lo posible: "es la condición que deben cumplir los entornos, procesos, bienes, productos y servicios, así como los objetos, instrumentos, herramientas y dispositivos, para ser comprensibles, utilizables y practicables por todas las personas en condiciones de seguridad y comodidad y de la forma más autónoma y natural posible".
} 
El primero de ellos, poco problemático al relacionarse con una vieja máxima jurídica ("ad impossibilia nemo tenetur"), justifica la falta de accesibilidad en el estado del conocimiento y la diversidad humana. La accesibilidad puede encontrar sus límites en el estado de la ciencia y la técnica $y$, también, en la posibilidad de conocer la diversidad humana.

El segundo sentido, ya más problemático, tiene que ver con actitudes. La exigencia de lo posible se traduce en exigencia de razonabilidad en un sentido particular. $Y$ es que, existen ámbitos sociales en los que el proceso de implementación del modelo social como enfoque general de tratamiento de la discapacidad es más lento y requiere una modificación muy sensible de su estructura. Así por ejemplo, la consecución de un mercado laboral abierto e inclusivo choca con una concepción del trabajo capacitista y esencialmente orientada al logro de beneficios empresariales. El modelo social exige un cambio de esta concepción y esto es difícil lograrlo en un breve espacio de tiempo. Y algo parecido ocurre en el ámbito educativo. Obviamente esto no quiere decir que no exista la obligación de ir hacia un mercado laboral inclusivo o hacia un sistema educativo inclusivo. $\mathrm{Ni}$ tampoco que debamos permanecer impasibles ante situaciones en las que los derechos de las personas con discapacidad no se satisfacen. Simplemente se trata de ser conscientes de las dificultades que tiene en estos ámbitos la satisfacción de la obligación del diseño universal y entender como una vía temporal de su superación puede ser la realización de ajustes razonables, siempre y cuando se haya probado que tampoco es posible realizar el diseño universal "concreto" (esto es el que se dirige a un grupo).

Se trata de un límite problemático porque dependiendo de su justificación, será asumible o no. En cierto sentido, esta posibilidad la contempla también el Comité sobre los derechos de las personas con discapacidad, aunque proyectado en unos ámbitos para mi mucho más discutibles, cuando en su Comentario general núm. 6 sobre Igualdad y No Discriminación, dice: "Dado que la realización gradual de la accesibilidad en el entorno construido, el transporte público y los servicios de información y comunicación puede llevar tiempo, cabe utilizar ajustes razonables entre tanto como medio para facilitar el acceso a una persona, por ser una obligación inmediata" (punto $42)^{23}$. Ahora bien, este límite y esta argumentación se vuelve aún más problemática cuando se presenta en términos económicos. Y esto suele ocurrir en la normativa ${ }^{24}$. Más adelante me referiré a esa proyección.

23 Disponible en:

https://tbinternet.ohchr.org/_layouts/15/treatybodyexternal/Download.aspx?symbo Ino $=$ CRPD $/ C / G C / 6 \&$ Lang $=$ en

24 Véase por ejemplo el artículo 7 referido a la carga desproporcionada del Real Decreto 1112/2018, de 7 de septiembre, sobre accesibilidad de los sitios web y aplicaciones para dispositivos móviles del sector público. 
El tercero de los sentidos, también problemático, tiene que ver con las consecuencias. En este caso, la exigencia de lo posible se traduce en exigencia de razonabilidad y proporcionalidad, y requiere tener en cuenta cómo afecta la accesibilidad a los derechos y cuál es su coste. Ahora bien, se trata de dos cuestiones que no pueden separarse, estando la segunda condicionada por la primera. Como he señalado, más adelante volveré sobre ello.

Los límites de lo razonable, que hemos visto que aparecen ya al hilo de los anteriores, adquieren significado en los ajustes. $Y$ es que la justificación del ajuste exige su razonabilidad en dos momentos. En el primero, lo razonable del ajuste radica en la existencia de una falta de accesibilidad justificada y por lo tanto no discriminatoria; en el segundo, lo razonable del ajuste radica en que no se traduce en una carga indebida o desproporcionada.

En todo caso, la razonabilidad no puede ser una válvula de escape de la exigencia del diseño universal y convertirse en una estrategia que permita ocultar verdaderos casos de discriminación.

Es habitual encontrarse en la regulación de los ajustes criterios a tener en cuenta a la hora de determinar su razonabilidad. Así por ejemplo, el art. 66,2 de la LGDPD, señala: "A efectos de determinar si un ajuste es razonable, de acuerdo con lo establecido en el artículo 2.m), se tendrán en cuenta los costes de la medida, los efectos discriminatorios que suponga para las personas con discapacidad su no adopción, la estructura y características de la persona, entidad u organización que ha de ponerla en práctica y la posibilidad que tenga de obtener financiación oficial o cualquier otra ayuda....".

Ahora bien, a la hora de determinar la idea de razonabilidad, en el marco de la accesibilidad y, más concretamente en los ajustes, hay que diferenciar según estemos en presencia de la accesibilidad en un sentido restringido o en un sentido amplio. Es decir, la razonabilidad, y con ello los límites al ajuste, serán diferentes según estemos ante la accesibilidad como derecho singular o ante la accesibilidad como contenido esencial de un derecho. Y es que la relevancia del ajuste razonable en el marco de la accesibilidad en sentido restringido es menor que la del ajuste razonable en el marco de la accesibilidad en sentido amplio. En este segundo caso, estamos dentro del discurso de los derechos, lo que exige, al menos, tener en cuenta dos tipos de consideraciones.

La primera de ellas tiene que ver con la exigencia de proporcionalidad, criterio presente a la hora de valorar la limitación de los derechos. Esta exigencia, en lo referente al ajuste supone: (i) examinar si los bienes que se sacrifican con el ajuste pueden ser satisfechos con otras medidas o solo dejando de realizar el ajuste, (ii) evaluar si hay medidas (ajustes) mejores; (iii) comparar las ventajas y sacrificios sobre los derechos que supone su adopción.

En este sentido, para determinar la razonabilidad del ajuste, en términos generales, habrá que tener en cuenta: a) los derechos que se sacrifican por realizar el ajuste; b) la existencia de medidas 
alternativas que pueden contrarrestar los efectos del ajuste; c) la discriminación que produce realizar o no el ajuste; d) el coste del ajuste.

La segunda de las consideraciones se refiere a la fuerza del argumento del coste. $Y$ es que, la cuestión de los costes tiene un alcance diferente dependiendo de que estemos en la accesibilidad como derecho o la accesibilidad como contenido esencial de los derechos.

Es evidente que los derechos han estado siempre limitados por su efectiva posibilidad económica de realización. Tradicionalmente se habla de límites materiales de los derechos para aludir a condicionantes que imposibilitan la satisfacción de los bienes o necesidades que están detrás.

Entre los ejemplos más utilizados a la hora de referirse a los límites materiales se encuentra la alusión a la escasez. Ahora bien, el significado de la escasez como límite material de los derechos debe intentar ser completamente a-valorativo. En este sentido, debe ser expresión de la escasez natural y no de una escasez construida, esto es, aquella que tiene su origen en decisiones humanas, en opciones que sitúan algún otro bien que es considerado como más relevante 25 . En estos casos, el límite a un derecho se produce no porque realmente sea imposible satisfacerlo, sino porque se sitúa a ese derecho por debajo de otro bien. Así, realmente es un caso de ponderación entre dos derechos o bienes.

La atención al coste económico como límite a los derechos se ha producido también de la mano de la llamada "reserva de lo posible". La expresión reserva de lo posible tiene su origen en Alemania a comienzos de los años setenta ${ }^{26}$ para recalcar la dependencia de los derechos económicos sociales y culturales de la capacidad económica de Estado y con ello para dejar sin justificación, por irrazonable, la satisfacción de estos cuando exijan un desembolso económico desproporcionado ${ }^{27}$.

Ahora bien, limitar un derecho por su coste excesivo no es un argumento que pueda tener cabida en el discurso de los derechos, salvo que se demuestre que dicho coste daña de manera insoportable otros derechos. Y en este punto lo relevante no es el coste en sí sino la afectación al derecho. La economía es un instrumento que, como tal, debe estar al servicio de los derechos y no éstos al servicio de la economía.

\footnotetext{
${ }^{25}$ Vid. ANSUÁTEGUI, F.J., "Algunas reflexiones sobre la visión integral de los derechos", en Estado \& Direito, n. 7-0, 1991-92, pp. 147 y ss.

26 En concreto, suele señalarse como primera sentencia en la que se recoge esta cláusula la dictada en 1972 y reconocida como numerus clausus. El argumento de la reserva de lo posible desde ese momento ha estado en tensión con el argumento del mínimo existencial. Vid. GOMES CANOTILHO, J.J., Direito constitucional e teoria das Constituiçao, Almedina, Coimbra 1998, p. 439.

27 Vid. ANSUATEGUI ROIG, F.J., Rivendicando $i$ diritti social, trad. de P. Chiarella, Edizioni Scientifiche Italiane, Napoli 2014, pp. 24 y ss.
} 
Un derecho puede encontrar sus límites en un coste excesivo siempre y cuando ese coste se exprese como insatisfacción de otros derechos. De esta forma, como he señalado en otro lugar, la utilización "de un argumento basado en un coste desproporcionado del ajuste, deberá ser examinado con mucha precaución e incluso considerarlo carente de justificación cuando ese coste no conlleve una insatisfacción real y evidente de derechos humanos de otras personas. Esto es, el coste como argumento independiente del disfrute de los derechos no puede tener cabida aquí. Su uso, como argumento admisible en el discurso de los derechos, requiere de su conexión con estos (en el sentido de expresar una limitación de los derechos de otros). Pero además, deberá evaluar el coste que conlleva la insatisfacción del bien en términos de falta de inclusión o de segregación"28.

La construcción del ajuste razonable y sus límites que acabo de exponer, se enfrenta a la manera en la que concibe esta institución el Comité sobre los Derechos de las Personas con Discapacidad. Y es que el Comité, en su Comentario General núm. 6, sobre Igualdad y No Discriminación ${ }^{29}$, señala que la obligación de realizar el ajuste posee dos partes: "la primera impone una obligación jurídica positiva de proporcionar ajustes razonables, que constituyen una modificación o adaptación que sea necesaria y adecuada, cuando se requiera en un caso particular para garantizar el goce o ejercicio de los derechos de una persona con discapacidad. La segunda parte asegura que los ajustes requeridos no impongan una carga desproporcionada o indebida al garante de los derechos" (punto 25).

A partir de aquí, en el mismo punto señala que "“ajustes razonables' es un único término y 'razonables' no debe interpretarse erróneamente como una cláusula de excepción". Y sigue: "Por el contrario, la razonabilidad de un ajuste hace referencia a su pertinencia, idoneidad y eficacia para la persona con discapacidad. Por tanto, un ajuste es razonable si logra el objetivo (o los objetivos) para el que se realiza y si está diseñado para satisfacer los requerimientos de la persona con discapacidad". En este sentido, para el Comité, la razonabilidad del ajuste tiene que ver con su pertinencia, idoneidad y eficacia (por cierto, términos que se usan normalmente para identificar el principio de proporcionalidad que es algo que parece eludir en este momento el Comité), pero no con su coste. Para el Comité: "La "carga desproporcionada o indebida" debe entenderse como un concepto único que establece los límites de la obligación de proporcionar ajustes razonables".

En el punto 26 de las Observaciones se refiere a algunos de los elementos que guían la aplicación de la obligación de realizar ajustes

\footnotetext{
28 DE ASIS, R., Sobre discapacidad y derechos, cit., p.124.

29 Disponible en:

https://tbinternet.ohchr.org/_layouts/15/treatybodyexternal/Download.aspx?symbo Ino $=$ CRPD $/ C / G C / 6 \&$ Lang $=$ en
} 
razonables. De su lectura, parece deducirse que la razonabilidad del ajuste se produce cuando se busca eliminar barreras a derechos (lo que he denominado en algún momento como límites de lo necesario) y cuando es factible (lo que he denominado como límites de lo posible). Por su parte, en la aplicación del ajuste razonable habrá que examinar si impone una carga desproporcionada, para lo cual "hay que evaluar la proporcionalidad que existe entre los medios empleados y la finalidad, que es el disfrute del derecho en cuestión". $Y$ en este punto se señala que: "Entre los posibles factores que deben tenerse en cuenta figuran los costos financieros, los recursos disponibles (incluidos los subsidios públicos), el tamaño de la parte que ha de realizar los ajustes (en su integralidad), los efectos de la modificación para la institución o empresa, las ventajas para terceros, los efectos negativos para otras personas y los requisitos razonables de salud y seguridad".

De todo lo anterior se deduce la posibilidad de que puedan darse situaciones en la que un ajuste razonable no se lleve a cabo por su coste. Algo así como que el ajuste era razonable pero la carga desproporcionada. Pues bien, esta manera de entender el ajuste lo separa del discurso de los derechos humanos y es difícilmente compatible con la idea de que la denegación del ajuste produce discriminación (que es algo que está meridianamente claro en la Convención y que la Observación desde el principio y a lo largo de todo su texto defiende).

\section{3.- BIBLIOGRAFÍA}

AA.VV., Historia de los derechos fundamentales, Tomo I, Tránsito a la modernidad. Siglos XVI y XVII, (dirigido por Gregorio PecesBarba y Eusebio Fernández), Universidad Carlos III-Dykinson, Madrid 1998.

ANSUÁTEGUI, F.J., "Algunas reflexiones sobre la visión integral de los derechos", en Estado \& Direito, n. 7-0, 1991-92.

ANSUATEGUI ROIG, F.J., Rivendicando i diritti social, trad. de P. Chiarella, Edizioni Scientifiche Italiane, Napoli 2014.

CAMPOY, I. (ed.), Los derechos de las personas con discapacidad, Debates del Instituto Bartolomé de las Casas, n.2, Dykinson, Madrid 2004.

Comité Económico y Social Europeo (CESE), Dictamen de 21 de enero de 2014, sobre "La accesibilidad como un derecho humano para las personas con discapacidad", ponente Yannis Vardakastanis, Disponible en:

https://eur-lex.europa.eu/legalcontent/ES/TXT/?uri=CELEX\%3A52013IE3000\&from=EN\&lang3 $=$ choose\&lang $2=$ choose\&lang $1=E N$

Comité sobre los Derechos de las Personas con Discapacidad, Comentario General núm.2, Disponible en: 
https://tbinternet.ohchr.org/_layouts/15/treatybodyexternal/Downloa d.aspx?symbolno=CRPD/C/GC/2\&Lang=en).

Comité sobre los Derechos de las Personas con Discapacidad, Comentario General núm.6, Disponible en:

https://tbinternet.ohchr.org/_layouts/15/treatybodyexternal/Downloa d.aspx?symbolno $=$ CRPD/C/GC/6\&Lang =en

DE ASÍS, R., "Hacia una nueva generalización de los derechos. Un intento de hacer coherente a la teoría de los derechos", en CAMPOY, I. (coord..), Una discusión sobre la universalidad de los derechos y la inmigración, Dykinson, Madrid 2006.

DE ASIS, R., Sobre la accesibilidad universal en el Derecho, Dykinson, Madrid 2007.

DE ASIS, R., Sobre discapacidad y derechos, Dykinson, Madrid 2013.

DE ASÍS, R., "El eje de la accesibilidad y sus límites", en Anales de Derecho y Discapacidad, núm. 1, 2016

FERNÁNDEZ, E., Teoría de la justicia y derechos humanos, Debate, Madrid 1984.

GIMÉNEZ GLUCK, D., Juicio de igualdad y Tribunal Constitucional, Bosch, Barcelona 2004.

GOMES CANOTILHO, J.J., Direito constitucional e teoria das Constituiçao, Almedina, Coimbra 1998.

KALBAG, L., Accesibility for Everyone, A Book Apart, New York 2017.

MARTINEZ PUJALTE, A-L., Derechos fundamentales y discapacidad, CINCA, Madrid 2015.

PECES-BARBA, G., "La moralidad de los derechos humanos", en Tiempo de Paz, n. 29-30, 1993.

PÉREZ LUÑO, A.E., "La universalidad de los derechos humanos", en LÓPEZ GARCÍA, J.A. y DEL REAL, J.A., Los derechos: entre la ética, el poder y el Derecho, Dykinson, Madrid 2000. 